\title{
Configurações
}

Revista de sociologia

$25 \mid 2020$

Debater o desenvolvimento: questões, dilemas e alternativas

\section{Serviço social e sustentabilidade: A abordagem ambiental como quadro de intervenção dos assistentes sociais}

Social work and sustainability: The environmental approach as an intervention framework for social workers

Travail social et durabilité: l'approche environnementale en tant que cadre d'intervention des assistants sociaux

Francisco Xabier Aguiar Fernandéz e Xoán Lombardero Posada

\section{(2) OpenEdition}

Journals

\section{Edição electrónica}

URL: http://journals.openedition.org/configuracoes/9013

DOI: 10.4000/configuracoes.9013

ISSN: 2182-7419

\section{Editora}

Centro de Investigação em Ciências Sociais

\section{Edição impressa}

Paginação: 154-169

ISSN: 1646-5075

\section{Refêrencia eletrónica}

Francisco Xabier Aguiar Fernandéz e Xoán Lombardero Posada, « Serviço social e sustentabilidade: A abordagem ambiental como quadro de intervenção dos assistentes sociais », Configurações [Online], 25 | 2020, posto online no dia 23 junho 2020, consultado o 25 junho 2020. URL : http://

journals.openedition.org/configuracoes/9013; DOI : https://doi.org/10.4000/configuracoes.9013 
Fernandéz, Francisco Xabier Aguiar; Posada, Xoán Lombardero - Serviço social e sustentabilidade: A abordagem ambiental como quadro de intervenção dos assistentes sociais. Configurações, vol. 25, 2020, pp. 154-169.

\title{
Serviço social e sustentabilidade: A abordagem ambiental como quadro de intervenção dos assistentes sociais
}

\author{
FRANCISCO XABIER AGUIAR FERNÁNDEZ * \\ Universidade de Vigo (Galiza-Espanha) \\ XOÁN LOMBARDERO POSADA** \\ Universidade de Vigo (Galiza-Espanha)
}

\begin{abstract}
Resumo
A crise ambiental e social global de que padece o planeta evidencia a interseção entre desigualdade, vulnerabilidade e injustiça ambiental. Neste trabalho realizar-se-á uma panorâmica sobre o impacto da abordagem ecológica na disciplina e profissão do serviço social. Partindo das primeiras contribuições explícitas a partir da década de 1970, serão tratados os vínculos desta perspetiva com o serviço social. A seguir, detemo-nos nas elaborações mais completas da década de 1980, abordando depois as suas contestações e réplicas, com ênfase na abordagem eco-crítica A aproximação prática a estes paradigmas vincula-se com outros métodos da profissão, designadamente com a advocacy ou prática política.
\end{abstract}

Palavras-chave: Crise, ambiente, serviço social, paradigma eco-crítico, politização.

\footnotetext{
Abstract

Social work and sustainability: The environmental approach as an intervention framework for social workers

The global environmental and social crisis that the planet suffers demonstrates the intersection between inequality, vulnerability and environmental injustice. In this article an overview of the impact of the ecological approach on the subject and profession of social work will be carried out. Starting with the first explicit contributions in the 1970s, the links of this perspective to social work will be discussed. Next, we will contemplate the most complete elaborations from the 1980s, and then address their challenges and replicas, with emphasis on the eco-critical approach. The practical approach to these paradigms is linked to other methods of the profession, in particular with advocacy or political practice.

* E-mail: francisco.aguiar@uvigo.es

** E-mail: xlombardero@uvigo.es
} 
Keywords: Crisis, environment, social work, eco-critical paradigm, politisation.

Résumé

Travail social et durabilité: l'approche environnementale en tant que cadre d'intervention des assistants sociaux

La crise environnementale et sociale globale que subit la planète témoigne du recoupement des inégalités, des vulnérabilités et des injustices environnementales. Dans cet article, un aperçu de l'approche écologique sur la discipline et la profession du travail social sera réalisé. Les liens de cette perspective écologique avec les débuts du travail social seront traités en prenant pour point de départ les premières contributions explicites à partir des années 1970. Nous nous intéresserons ensuite aux élaborations les plus complètes des années 1980, puis aborderons les réponses et débats, en mettant l'accent sur l'approche éco-critique. L'approche de ces paradigmes est liée à d'autres méthodes de la profession, notamment avec l'advocacy ou la pratique politique.

Mots-clés: Crise, environnement, travail social, paradigme éco-critique, politisation.

\section{Introdução}

Um dos problemas mais graves que a humanidade enfrenta, podendo ameaçar mesmo a própria sobrevivência da espécie humana, é a progressiva degradação do ambiente. Embora as causas sejam múltiplas, quiçá a mais relevante está relacionada com o desenvolvimentismo económico sem limites que se estendeu nas duas centúrias anteriores, marcadas pela propagação do capitalismo, em especial nas últimas décadas, a regiões do planeta onde não estava instaurado (Ribeiro, 2017). A crise ambiental tem impactos muito relevantes para a prática do serviço social. A deterioração nos meios de vida afetam de maneira direta a saúde e o bem-estar das populações. Aliás, esta questão pode ser vista do ponto de vista dos direitos humanos e do estreito relacionamento entre justiça social e ambiental (Mckinnon e Alston, 2016). Assim, a injustiça social e a exploração da natureza são originadas pela mesma forma de pensamento (Coates, 2003). Os problemas ambientais não são unicamente os que derivam do aproveitamento prejudicial e irracional dos recursos naturais, abarcando também os problemas que emanam de más práticas em matéria de administração e produção, e em geral, dos mecanismos de acumulação do capitalismo que geram empobrecimento.

Do ponto de vista do serviço social, diversos autores centraram as suas reflexões no papel da disciplina no impacto social do aquecimento global e nos seus elevados custos a larga escala para as famílias e as comunidades (Alston e Besthorn, 2012; Coates e Gray, 2011; Dominelli, 2012). Alguns destes efeitos são as deslocações de pessoas por falta de alimentos, água ou habitação (Alston e Kent, 
2004; Besthorn e Myer, 2010) ou o aumento da mortalidade de grupos vulneráveis relacionada com problemas de saúde (Lam, 2007). Por outro lado, as pessoas com menos recursos económicos ou capital social podem ser forçadas a aceitarem viver com riscos que seriam inaceitáveis para outras pessoas (Peeters, 2012a). Autores como Hoff e McNutt (1994), Dominelli (2012) ou McKinnon e Alston (2016) sustentam que o trabalho social tem de transitar para novos reptos onde o bem-estar individual e social adotem novos modelos de sustentabilidade e proteção do meio ambiente.

Neste trabalho partimos da hipótese de que as questões meio-ambientais não são alheias à tradição histórica do serviço social e se encontram na própria origem do serviço social como profissão. Vamos ver no entanto que as contribuições explícitas neste campo e a sua integração como "questão ambiental" não aparecem até à década de 1980, dando forma, todavia, a duas concepções não antagónicas, mas divergentes: uma vinculada à teoria dos sistemas e outra relacionada com a visão eco-crítica. Embora ambas sejam abordadas, dar-se-á especial ênfase à segunda. Finalmente, serão expostas algumas limitações encontradas na prática do serviço social eco-crítico e estabelecer-se-ão vínculos com a denominada prática política ou advocacy na profissão.

\section{0 serviço social e questão meio-ambiental: uma ligação de longa data}

Närhi e Matthies (2016) sustentam que o pensamento ecológico no serviço social remonta aos seus inícios. Os autores indicam que existiram duas maneiras de entender o relacionamento do serviço social com o meio, e que estas poderiam resumir-se em duas linhas de pensamento simbolizadas por duas das suas pioneiras, Mary Richmond (1861-1928) e Jane Addams (1860-1935). A primeira autora enfatizava a importância da interação social e das redes sociais no serviço social de casos, estabelecendo o foco dominante no meio social da pessoa, perspetiva que mais tarde conhecer-se-ia como "pessoa no seu meio"; a segunda colocou o foco no contexto urbano, dando maior relevância ao ambiente físico e às condições ambientais. No entanto, a prática do serviço social raramente tem estado vinculada ao contexto biofísico ou às organizações que focam a sua intervenção no meio ambiente e na sustentabilidade ecológica. Por isso, os problemas ecológicos não foram uma preocupação intrínseca na profissão (Peeters, 2012a).

Gray e Coates (2013) associam esta inconsistência à própria origem do serviço social como profissão num contexto em que, nas sociedades ocidentais, o capitalismo acelerava as suas acumulações primordiais (Netto, 1992). Os distintos impactos sobre a natureza eram, simplesmente, entendidos como atribuições humanas e como formas não apenas de controlo mas de domínio positivo da espécie sobre os fatores ambientais e o próprio espaço geológico, até então incontrolável e fora do 
alcance da humanidade. Esta mentalidade, devedora das Luzes, ainda permeia nos nossos dias amplos setores da profissão (Ferguson, loakmidis e Lavalette, 2018). Por outro lado, esta literatura reconhece uma atenção primordial relacionada com as pessoas e relativa às condições precárias de habitação e espaços insalubres que chamaram a atenção das pioneiras do serviço social. Além disto, existia, para estas fundadoras, um vincado interesse pela dimensão relacional entre as pessoas: os indivíduos não só viviam fisicamente em condições inadequadas, como esta circunstância, unida às extensas jornadas laborais, fazia com que o relacionamento e a vida social fossem muito limitados; daí a necessidade manifesta da existência de espaços de convivência e de aprendizagem cívica, cultural e social (Levine, 1971; Knight, 2010).

Para Gray, Coates e Hetherington (2013) existem três períodos no compromisso do serviço social com os problemas ambientais. O primeiro período, a partir de 1970, implicou a adaptação da focagem ecológica ao trabalho social, reconhecendo a importância do meio ambiente para o desenvolvimento individual e comunitário, conquanto se tenham considerado principalmente as questões sociais do meio. O segundo período compreende o final da década de 1980 e a de 1990, debaixo da influência do movimento de justiça ambiental e dos problemas relacionados com a degradação ambiental e as suas consequências na população. Finalmente, o terceiro período, em que nos encontramos, caracteriza-se por uma ampliação do foco de interesse pelo respeito pelo meio natural e os seus impactos no bem-estar humano.

Como consequência da emergente preocupação pela crise ecológica e o crescimento dos movimentos ecologistas na década de 1970, surge no serviço social uma perspetiva que questiona as consequências ambientais do desenvolvimento e a moderna sociedade industrial (Närhi e Matthies, 2001). Desde então, podem perfilar-se duas direções teóricas no serviço social ecológico que continuam a ser utilizadas na categorização da literatura atual (Närhi e Matthies, 2016): (i) a aproximação teórica dos sistemas, com a ênfase principal colocada no meio social e no pensamento holístico; (ii) a perspetiva eco-crítica, que translada para o serviço social o impacto dos novos movimentos ecologistas e a crítica ecológica à moderna sociedade industrial. Seguindo Närhi e Matthies (2016), comparando as ideias-força de ambas propostas, a teoria dos sistemas considera o meio natural como um meio abstrato, enquanto a perspectiva eco-crítica considera o meio em primeiro lugar como um meio natural. Em ambas tradições o relacionamento dos humanos com o meio é interativo. No entanto, no primeiro caso a pessoa é considerada como parte de um sistema holístico, incluindo os níveis micro, meso e macro, enquanto no segundo o indivíduo é parte da natureza e do sistema holístico do planeta. Assim, a teoria dos sistemas representa uma estratégia de adaptação enquanto a perspectiva eco-crítica seria uma estratégia de mudança social que não aceita a ordem estabelecida. 


\section{Começos da década de 1980. Primeiros impactos da teoria ecoló- gica no serviço social}

As primeiras aproximações explícitas relacionadas com a questão ambiental no serviço social vieram da mão da teoria geral dos sistemas, que traça uma analogia entre o funcionamento da sociedade e o sistema biológico e, dentro dele, da pessoa. Os modelos causais, derivados das ciências exatas e do racionalismo, não seriam adequados para tratar com entes de alta complexidade como os humanos. Derivada de von Bertalanffy, biólogo de formação com produção científica entre as décadas de 1920 e 1960, a teoria dos sistemas foi introduzida no serviço social por Frank Hankins, do Smith College School of Social Work (Healy, 2014). Antes do termo "dos sistemas" ser proposto, a ideia não era alheia à profissão, ao enquadrar-se dentro da perspetiva da "pessoa no seu meio" divulgada por Mary Richmond. As contribuições de Goldstein (1973), Pincus e Minahan (1973), Siporin (1975) e sobretudo Germain e Gitterman (1980) assentaram a teoria na profissão. Mas a teoria dos sistemas foi questionada porque a proposta da "pessoa no seu meio" não dava suficiente relevância ao meio ambiente e à natureza (Coates e Grey, 2011; Besthorn, 2012; Dominelli, 2012). Assim, a crítica dirigiu-se à sua neutralidade, já que o relacionamento entre o meio ambiente e o ser humano não é contemplada como questão política (Närhi e Matthies, 2001; Coates e Gray, 2012).

Em qualquer caso, Gitterman e Germain (1980) adaptaram para o serviço social ecológico noções derivadas da biologia e das comunidades bióticas. Nestes contributos são incluídos flora e fauna, bem como as diferentes formas do entorno físico, tais como as alterações naturais, o clima e o terreno. O serviço social ecológico entende que as pessoas interagem em contextos culturais, físicas e sociais. Assim, o meio ambiente social compreende a família, as amizades e os círculos de relacionamento destes; incluem-se aqui os grupos amplos determinados pelas organizações, instituições e a comunidade, que constituem os cenários físicos. A própria sociedade integra-se também neste ponto, incluídas as estruturas políticas, económicas e os diferentes quadros legislativos. No que diz respeito ao ambiente físico, este inclui o mundo natural, as edificações e estruturas construídas pela humanidade, os espaços gerados por essas estruturas, assim como as sequências e ritmos da biologia ambiental e humana. Por seu turno, a cultura faz parte tanto do ambiente como da própria pessoa, e tem como expressão o sistema de valores, crenças, normas e linguagem da cada pessoa (Gitterman e Germain, 1980). As pessoas, as suas condutas e interações só podem ser compreendidas tendo em conta as ligações de todos os fatores anteriores, acrescentando-se a estes conceitos os de habitat e nicho (Gitterman e Germain, 1980, pp. 53-57).

O habitat engloba os locais onde os organismos, também humanos, vivem e se desenvolvem. Ao não proporcionarem possibilidades de ação comunitária ou pessoal, ou ao interferirem com funções essenciais da vida relacional, os diferentes 
habitats tornam-se produtores de isolamento, angústia e desorientação, impedindo funções básicas da vida pessoal-familiar e comunitária. Por seu turno, entende-se por nicho a posição que as diferentes espécies de organismos ocupam numa comunidade biótica; destarte, no plano social, a referência tem que ver com a posição que os indivíduos ou os grupos ocupam na estrutura de relações, sendo esta uma elaboração histórica e mutável. Existem características que, num momento determinado, são valorizadas, enquanto outras são preteridas. Os nichos relacionam-se tanto com o quadro geral como com o leque de direitos sociais que uma dada sociedade é capaz de gerar, entendendo-se que estes direitos não são outorgados mas adquiridos pela ação e engajamento dos indivíduos em diversas causas (Gitterman e Germain, pp. 54-58).

\section{0 paradigma do serviço social eco-crítico}

O serviço social, nos últimos anos, tem expandido as suas considerações teóricas e intervenções práticas para o meio físico: as conexões com o planeta e todas as formas de vida foram mais centrais no discurso da disciplina. Autores como Peeters (2012a, 2012b, 2016), põem o acento na necessidade de se desenvolver o paradigma ecológico com uma ênfase crítica. De facto, a partir da segunda década do presente século, os debates sobre esta nova aproximação ambiental do serviço social tem-se enraizado em diferentes países e línguas, apoiando-se em variados conceitos. Evocando algumas das denominações emergentes no debate, podem-se identificar as seguintes: (i) ênfase no serviço social ecológico (ecological social aproach in social work) utilizado por autores como Närhi (2004) ou Peeters (2012b); (ii) serviço social profundamente ecológico (deep ecological social work) de Besthorn (2003, 2012); (iii) serviço social eco-espiritual (eco-spiritual social work) em autores como Gray e Coates (2013); (iv) serviço social verde (Green social work) em Dominelli (2012); (v) serviço social socio-ecológico (Social ecological Social work) em Peeters (2012); (vi) ou serviço social ambiental (environmental Social work) utilizado por Gray, Coates e Hetherington (2013). Seguindo Närhi e Matties (2016), todos estes conceitos têm em comum os seguintes elementos: (i) são continuadores da tradição do serviço social ecológico; (ii) retomam a tradição do serviço social político e de mudança social formulada por Jane Addams; (iii) desafiam o serviço social hegemónico exigindo um novo paradigma ecológico e a transição da sociedade; (iv) propõem um pensamento de perspetiva global, mas ditigido a ações nas comunidades locais; e (v) concebem o ser humano como parte da natureza.

Para Alston, Whittenbury e Western (2016) existe, no entanto, uma lacuna quando se consideraram os elementos sociais da sustentabilidade, já que geralmente se acentuam os seus componentes económicos e ambientais, enquanto 
só de forma parcial se considera o equilíbrio entre ambiente e justiça social. No serviço social a linguagem ecológica é frequentemente usada, critica-se, como uma aproximação convencional que esquece o meio físico nos seus modelos de implementação e avaliação da prática (Närhi e Matthies, 2016). Nesta nova perspectiva do serviço social ecológico ou verde, os assistentes sociais tomam em consideração diversos aspectos das violações dos direitos humanos, as desigualdades geradas pelos sistemas económicos, a falta de reconhecimento dada à diversidade cultural ou aos conhecimentos indígenas e as tentativas de reconstrução de comunidades sem ter em atenção a sua resiliência ou a sustentabilidade (Coates, 2003; Norton, 2012).

À medida que a perspetiva ecológica do serviço social emerge, oferece aos profissionais uma participação mais ativa no debate internacional sobre os problemas e catástrofes naturais e a mudança climática. Matthies e Nähri (2017) consideram o serviço social ecológico como parte de uma transição eco-social mais abrangente e interdisciplinar das sociedades em direção à sustentabilidade, equilibrando o desenvolvimento económico e social com os recursos limitados do ambiente natural. Neste sentido, seguindo Peeters (2016), o papel dos assistentes sociais é o de capacitar as pessoas, construir capital social e resiliência. Para isso, devem entender de forma crítica o relacionamento existente entre as pessoas e o seu meio natural, começando onde a pessoa e a comunidade estão e navegando entre as complexas políticas que resultam de diferentes leis, governos e interesses. Este objetivo configura o meio ambiente como um espaço socialmente construído que abarca realidades físicas e materiais, estruturas socioeconómicas, políticas e culturais e locais espirituais e emocionais que são compreendidos como um todo integrado no espaço em que os indivíduos desenvolvem as suas vidas num tempo real, simbólico e imaginário. Para Case (2017), também a resiliência comunitária é cada vez mais popular nos campos ambiental e de desenvolvimento comunitário, como uma estrutura conceptual apta a avaliar e desenvolver a capacidade das comunidades e a apoiar o bem-estar diante de mudanças, adversidades e riscos ambientais. Para este autor, enquanto o conceito de resiliência está bem estabelecido no serviço social, a "resiliência da comunidade" aínda permanece sub-examinada na literatura.

\section{A intervenção na práctica com uma focagem eco-crítica}

Autores como Schmiitz, Matiók, James e Sloam (2011) argumentam que o forte foco e interesse do serviço social nos direitos humanos, na justiça social e no fortalecimento de comunidades supõe uma base sólida para o compromisso com os processos colaborativos, criativos e globais que requerem as práticas ambientalistas. A questão é colocada considerando os possíveis modos de os assistentes sociais incorporarem o ambiente natural nas suas intervenções. Miller, Hayward e 
Shaw (2011) propõem um novo papel para o serviço social focalizado num balanço entre o apelo pragmático para se atender às necessidades humanas no meio social, ao mesmo tempo que trabalha para superar a separação artificial entre o social e o meio natural no paradigma da "pessoa no seu meio". Os autores consideram que, para isso, se deve: (i) insuflar no serviço social um entendimento holístico do relacionamento entre a sociedade humana e o ambiente; ii) examinar compreensivamente os problemas relacionados com a justiça ambiental e (iii) desenvolver métodos dirigidos a superar as desigualdades raciais e socioeconómicas.

Um dos primeiros trabalhos relevantes compreendendo as questões ambientais e o seu impacto, desde e para o serviço social, foi The Global Environmental Crisis: Implications for Social Welfare and Social Work (Hoff e McNutts, 1994), onde se indicam áreas e intervenções ambientais onde os assistentes sociais podem atuar. A revisão da literatura realizada por Coates e Gray (2011) revela que o serviço social ambiental incorpora um amplo leque de áreas temáticas para a prática profissional: (i) a intervenção em desastres e acontecimentos traumáticos; (ii) a intervenção em secas; (iii) o ativismo face à mudança climática; (iv) as respostas à exposição a agentes tóxicos e químicos, especialmente em populações desfavorecidas; (v) a segurança alimentar; (vi) o desenvolvimento económico sustentável e o capital social para a criação de emprego; (vii) a educação comunitária ambiental e ecológica; (viii) os combustíveis fósseis e a adaptação habitacional em comunidades empobrecidas; e (ix) os danos causados às pessoas e comunidades pela indústria e/ou pelas corporações transnacionais. Esta variedade de temas põe a relevância na diversidade de intervenções em que estão comprometidos os assistentes sociais.

No entanto, Molineux (2010), ao analisar o serviço social ecológico, conclui que a literatura centrada na prática é ainda vaga e desligada da interação diária. Num trabalho mais recente, Matthies et al. (2019) identificam uma importância crescente das inovações eco-sociais que interconectam aspectos ecológicos, económicos e objetivos sociais, e que muitas vezes surgem como pragmáticas soluções para necessidades locais. Para os autores, estas inovações ecossociais podem ser fontes relevantes para novas possibilidades de subsistência e bem-estar além do mercado de trabalho convencional, e são valiosas como precursoras para impulsionar a transição para a sustentabilidade a partir da prática do serviço social.

No entanto, as ocasiões para encetar esta prática, ainda em construção, abundam. Assim, na conhecida The choque doctrine, de Naomi Klein (2007), uma das teses principais é a de que os denominados desastres naturais são habitualmente utilizados por multinacionais ou por poderes económicos, mediante vias políticas, para impor reestruturações económicas, sem se ter em conta, pelo menos num primeiro momento, a posição dos cidadãos. Desse modo, as diferentes atuações realizam-se sem consulta ou participação prévia, debaixo do manto da alegada urgência de se intervir perante a emergência. A intervenção tenta ser associada ao carácter provisório do evento excepcional, preferencialmente num palco de 
opacidade. A atuação, que era provisória, torna-se depois definitiva ou de facto (os hospitais encerrados depois do furacão não reabrem ou fazem-no em novos moldes, as escolas afetadas pelo sismo não são reabilitadas, etc.). Além disso, para Pyles (2007), a revitalização da comunidade é um elemento frequentemente negligenciado na recuperação de desastres. A autora reviu algumas das iniciativas de desenvolvimento e organização da comunidade, em Nova Orleães após o furacão Katrina, e observou um foco excessivo dos asistentes sociais na intervenção pós-traumática de cariz psico-terapêutico. A falta de ênfase do serviço social na organização da comunidade é uma barreira ao desenvolvimento social em situações pós-desastre.

Herbert-Boyd (2007) numa obra de carácter histórico, mas com ligações ao presente, entende que os e as profissionais do serviço social podem, ora examinar o seu papel na ordem social, atuando como catalisadores de mudanças ou, pelo menos, como transmissores destas mudanças orientadas por e para políticas sociais progressistas, ou ao invés podem abraçar posições conservadoras, incutindo receios ou alimentando posicionamentos estáticos e ordeiros.

A definição de serviço social, adotada pela Federação Internacional de Serviço Social (IFSW) em Melbourne (2014), incide no compromisso da profissão com a "promoção do bem-estar humano" da "justiça" e da "sustentabilidade", e pelo trabalho com as "pessoas no seu entorno". A agenda global das Nações Unidas para o desenvolvimento sustentável Transformando nosso mundo: a Agenda 2030 para o desenvolvimento sustentável define um conjunto de 17 objetivos e oferece aos assistentes sociais uma oportunidade de redefinirem o seu papel na capacitação das pessoas e na sustentabilidade socioeconómica, nos direitos humanos e no meio ambiente. Em 2010, em Hong Kong, foi assumido um compromisso de ação conjunta (IFSW, Associação de Escolas de Serviço Social e Conselho Internacional de Bem-Estar Social) que levou à publicação conjunta da Agenda Global do Serviço Social e o Compromisso com o Desenvolvimento Social para a Ação. Igualmente, a Federação Internacional de Serviço Social publicou nos últimos anos vários documentos que oferecem ferramentas para profissionais, estudantes e educadores, com o objetivo de se avançar na agenda e na prática ecológica do serviço social, entre os quais podemos destacar o trabalho recente de Rinkel e Poweers (2019). Ao mesmo tempo, muitas conferências, congressos e publicações internacionais têm-se concentrado no desenvolvimento sustentável e na sua relação com o serviço social. Apesar disto, e considerando ainda o interesse que é suscitado pela questão ambiental, os assistentes sociais, na academia e em contexto profissional, tardam a chegar a um entendimento sobre a forma adequada de incorporar estes contributos na prática quotidiana. 


\section{Consenso e participação: alguns riscos}

Frequentemente, na tradição do serviço social, as comunidades são vistas como integradas e com uma conflitualidade limitada, sendo o objetivo da intervenção social o de se trabalhar num tipo particular de relacionamentos sociais, promovendo-se a partilha dos mesmos valores básicos e de projetos comuns de futuro (Peeters, 2016). Deste ponto de vista, o compromisso cívico é principalmente baseado na criação de experiências de igualdade e de processos de identificação e pertença. Construir comunidades coesas é visto como uma resposta à individualização e à fragmentação, favorecendo a vitalidade da sociedade civil. Muitas das iniciativas de desenvolvimento sustentável partilham este tipo de aproximação comunitária. Seguindo Jickling (1994), aprender para um desenvolvimento sustentável converte-se, então, num simples instrumento para a promoção de um determinado tipo de desenvolvimentismo indiferenciado. Esta visão acaba por ameaçar, a nível global, as vidas de grande parte da população mundial, em benefício das classes mais favorecidas (Peeters, 2012a). Uma perspetiva consensual da modernização ecológica ameaça assim os princípios essenciais do serviço social baseados nos direitos humanos e na justiça social e tende a marginalizar as vozes das pessoas empobrecidas.

Outro importante foco do serviço social é o fomento da participação como oportunidade para o desenvolvimento individual e coletivo. A sustentabilidade social requer participação e resiliência das pessoas e das comunidades. Neste sentido, as comunidades mais vulneráveis podem ver-se enredadas em dinâmicas alheias e não serem capazes de se movimentarem ou atuarem perante os seus problemas ambientais, por não disporem de serviços ou mecanismos que apoiem as suas iniciativas. Neste sentido, é conveniente ter em consideração as críticas pós modernas e pós-estruturais que põem em causa o caráter emancipador de muitos dos processos de participação que se levam a cabo na atualidade. Seguindo autores como Cooke e Kothare (2004) ou Quaghebeur, Masschelein e Guyen (2004), a participação cidadã pode converter-se numa nova tirania. A cidadania é estimulada a participar por si própria, mas, ao mesmo tempo, esta oportunidade é oferecida mediante o filtro doutras pessoas que estabelecem o modelo e as normas. Face a isto, o serviço social deveria estimular práticas participativas onde os cidadãos possam expor as suas preocupações e mesmo as suas dúvidas ou cepticismos quanto à sustentabilidade. Na hora de converter a sustentabilidade em objetivo político, o serviço social vincula o individual ao estrutural, e vai para além de uma limitada ação consensual, reconhecendo que o conflito é inevitável.

As e os assistentes sociais estão comprometidos com a justiça social. Para trabalhar em prol deste objetivo, dispõem de conhecimentos a respeito dos sistemas sociais e das influências estruturais que afetam os indivíduos e as 
comunidades. O serviço social, na sua relação com a sustentabilidade, deve ser concebido a partir de uma aproximação crítica e radical. Caso contrário, a sua aplicação na prática corre o risco de se converter em ação pragmática despolitizada: a finalidade principal do serviço social não é a de resolver os problemas sociais, mas sim a de contribuir para a transformação das condições sócio-políticas que produzem a injustiça (Dominelli, 2012).

\section{A politização do serviço social na resposta eco-crítica}

Focalizar o centro do serviço social na "pessoa no seu meio ambiente" requer converter os assuntos individuais e privados em matéria de preocupação pública. Sendo assim, um papel importante para os profissionais do serviço social reside em dar visibilidade à forma como a sustentabilidade é irreconciliável com os valores do modo de produção capitalista, fomentando uma reflexividade crítica (Silva, Sacramento e Mendoça, 2015). Para atingir o propósito da sustentabilidade, é necessário que um novo conceito de bem-estar social transcenda o materialismo e o individualismo e que o significado intrínseco da natureza nas sociedades humanas seja reconhecido. Ao operar desta forma, o serviço social verde (Dominelli, 2012), bem como outras formas progressistas de serviço social, apresentam-se explicitamente políticos. Constroem-se com os princípios do serviço social radical e anti-opressivo que identifica as escolhas políticas das pessoas dentro dos relacionamentos sociais desiguais em diferentes sentidos (Gill e Jack, 2007; Van Wormer et al., 2012). No entanto, atendendo à abordagem eco-crítica, a tendência ecológica convencional é também política, ainda que de modo implícito, ao ignorar os relacionamentos de poder existentes nas estruturas geopolíticas, sendo estas as que definem os problemas de identidade, os relacionamentos de poder e a distribuição de recursos. Autores como Souza et al. (2011) advertem para o fosso do pensamento social que tem sido produzido, seja sobre a questão ambiental, a crise ambiental ou a educação ambiental, hegemonicamente dirigidos por perspectivas acríticas, fundadas em análises fragmentadadas que desconsideram a totalidade das relações sociais e a reprodução da sociedade capitalista moderna. Silva (2010) trata a atuação do serviço social na gestão da "questão ambiental" a partir de um projeto ético-politico como ferramenta essencial para este, onde a dimensão ténico-operativa coloca as questões institucionais e profissionais num desafio constante. Para esta autora brasileira, no sentido teórico-metodológico, o serviço social que caminha numa direção crítica deve nortear-se por uma leitura crítica da "questão ambiental", apropriando-se da sua condição histórica e natural, rompendo com o fosso entre o social e a natureza. Enquanto prática ético-politica sintonizada com valores universalistas e emancipatórios, o desafio colocado à profissão significa indagar acerca dos determinantes dos processos sobre os quais 
ela é convocada a intervir, ligando os fenómenos imbricados no agravamento da "questão ambiental" e da desigualdade social.

Seguindo Payne (1995) a prática do serviço social é um relacionamento mútuo entre a mudança social e o desenvolvimento do bem-estar individual. O repto de uma transição para a sustentabilidade requer uma prática mais transformadora. Somente quando reconhecemos que os nossos atuais padrões de produção e consumo conduziram a um impasse de carácter estrutural, é que poderemos assumir que é necessária uma transição para uma sociedade sustentável, e que esta tem de ser muito diferente da que é proposta pelos atuais modelos dos países industrializados. Esta transição requer um processo de mudança profunda que afeta todos os âmbitos das nossas vidas. Em primeiro lugar, o trabalho social deve situar-se numa visão política da sustentabilidade e envolver-se ativamente no debate a respeito da mesma. Assim, um posicionamento crítico e um serviço social emancipador apresentam-se como as melhores vias profissionais para contribuir para a transformação e a sustentabilidade das comunidades, desde o local ao global, e como renovada resposta profissional às lógicas neoliberais que ameaçam o bem-estar das populações e a sustentabilidade dos territórios. Coincidimos com Abad e Martín (2015), quando afirmam que o serviço social deve tomar partido entre a lógica da ação social emancipadora e transformadora ou a lógica da assistência e o consenso.

A focagem eco-crítica permite aos assistentes sociais superar uma visão do bem-estar ocidental pensada "para" e limitada "a" uma parte minoritária da população mundial, a partir de uma visão antropocéntrica que não tem em conta os direitos da natureza. Para Peeters (2012), isto requer pelo menos a satisfação das seguintes condições: a desmaterialização da economia, o que significa uma substancial redução da exploração dos recursos naturais, a justa distribuição da riqueza e uma nova visão do bem-estar humano. No seu conjunto, a consecução destas condições exige uma mudança estrutural que requer transformações em todos os níveis da sociedade: ecológico, tecnológico, social, político e institucional.

Neste sentido, num trabalho sobre a advocacy na profissão, já em 1984, Ann Withorn indicava que os assistentes sociais devem enfrentar a dicotomia entre política e realizações concretas da prática. A neutralidade em nome do profissionalismo ou duma alegada precisão teórica é um suposto tão enganador como irreal (Silva e Ribeiro, 2015). Os vínculos entre objetivos políticos e programas sociais existem, embora não sejam explícitos. Apesar deste silêncio, a política social, inclusive a existência do próprio posto de trabalho do assistente social é uma opção política. É necessário não perder este vínculo para se ser capaz de distinguir e localizar as disfunções do sistema que se disfarçam através de procedimentos administrativos, técnicos ou burocráticos, enfim, formas de fazer passar por neutro aquilo que é fortemente ligado à decisão. Em terceiro lugar, a assunção da natureza política do serviço social nutre de conteúdo a profissão na relação com outras ocupações 
das ciências sociais. O aparente risco de se ser apontado como um "ativista" traz, é certo, o "incómodo" do conflito, no quadro de uma profissão já forjada e dotada institucionalmente de mecanismos regulatórios e de proteção. Em quarto lugar, o vínculo com o político confere profundidade, por um lado, e dever de precisão por outro, naquilo que queremos enunciar ou para o que queremos chamar a atenção (Withorn, 1984).

\section{A modo de conclusões}

Os vínculos do serviço social com as questões ambientais podem ser estabelecidos desde os primórdios da profissão, embora o reconhecimento e uma abordagem explícita façam parte sobretudo do último terço do século XX. No entanto, apesar dos avanços conseguidos nos últimos anos pela abordagem teórica e académica do paradigma eco-crítico, a prática do serviço social ambiental continua pouco desenvolvida, não obstante o crescente papel que as questões ambientais têm em todas as comunidades e para todas as pessoas do planeta. O desenvolvimento da perspectiva eco-crítica do serviço social e as ainda incipientes práticas que ela tem promovido proporcionam, em todo o caso, um enquadramento de referência que permite: (i) oferecer uma resposta ambiental justa e sustentável, (ii) questionar e neutralizar de forma propositiva as inércias desenvolvimentistas e patriarcais de longa data e (iii) retomar as tradições e saberes socialmente mais avançados da profissão.

Entendemos pois que a abordagem da questão ambiental pelo serviço social inclui elementos da prática e do ativismo político que interpelam o conjunto da profissão. Isto acontece devido à recolocação do meio físico no núcleo da problematização, estabelecendo um relacionamento causal entre justiça social e ambiental, e assumindo a consideração estrutural das desigualdades. No preâmbulo de um novo decénio, o desafio reside em que as e os assistentes sociais desenvolvam ou adaptem novas teorias vinculadas a este campo e, sobretudo, elaborem práticas devidamente fundamentadas para melhorar as suas capacidades, assegurando a sua inserção, tanto teórica como prática, no currículo formativo profissional.

\section{Referências bibliográficas}

ABAD, Begoña e MARTIN, Idoia (2015), “El Trabajo Social ante la crisis. Nuevos retos para el ejercicio profesional de los y las trabajadoras sociales". Cuadernos de Trabajo Social, 28 (2), 175-185. doi: http://dx.doi.org/10.5209/rev_CUTS.2015.v28.n2.48765.

ALSTON, Margaret e BESTHORN, Fred (2012), "Environment and sustainability". In Karen LYONS, Terry Hokenstad, Manohan Pawar, Nathalie Huegler e Nigel Hall (eds.), The Sage handbook of international social work, (pp.56-69), Londres, Inglaterra, Sage. 
ALSTON, Margaret e KENT, Jenny (2004), Social impacts of drought: A report to NSW Agriculture, Wagga Wagga, NSW, Centre for Rural Social Research, Charles Sturt University.

ALSTON, Margaret, WHITTENBURY, Kerri e WESTERN, Deb (2016), "Rural community sustainability and Social Work practice". In Jennifer McKinnon e Margaret Alston (eds.), Ecological Social Work Towards sustainability, (pp. 94-108), Londres, Inglaterra, Palgrave.

BESTHORN, Fred (2012), "Radical Equalitarian Ecological Justice: A social work call to action". In Mel Gray, John Coates e Tiani Hetherington (eds.), Environmental Social Work, (pp. 31-45), Nueva York, Routledge.

BESTHORN, Fred e MYER, Elizabeth (2010), "Environmentally displaced persons: Broadening social work's helping imperative". Critical Social Work, 11 (3), 123-138. Disponíbel em http:// www.uwindsor.ca/criticalsocialwork/environmentally-displaced-persons-broadening-social-work\%E122\%180\%199s-helping-imperative.

CASE, Robert (2017), "Eco-social work and community resilience: Insights from water activism in Canada". Journal of Social Work, 17 (4), 391-412. doi.org/10.1177/1468017316644695

COATES, John e GRAY, Mel (2011), "The environment and social work: An overview and introduction". International Journal of Social Welfare, 21(3), 230-238. doi:10.1111/j.1468-2397.2011.00851.x

COATES, John (2003), Ecology and social work: Toward a new paradigm, Halifax, NS, Fernwood.

COOKE, Bill e KOTHARY, Uma (2004), Participation: The New Tyranny?, Londres, Zed Books.

DOMINELLI, Lena (2012), Green social work: From environmental crises to environmental justice, Cambridge, Polity.

FERGUSON, Iain, IOAKIMIDIS, Vasilios e LAVALETTE, Michael (2018), Global social work in a political context, Bristol, Policy Press.

GERMAIN, Carel e GITTERMAN, Alex (1980), The Life Model of Social Work Practice, Nueva York, Columbia University Press.

GOLDSTEIN, Howard, (1973), Social Work practice: a unitary approach, Columbia, University of South Carolina Press.

GRAY, Mel e COATES, John (2013), “Changing values and valuing change: Towards an Ecospiritual perspective in social work", International Social Work, 56 (3), 356-368.

GRAY, Mel, COATES, John e HETHERINGTON, Tiani (eds.) (2013), Environmental Social Work, Londres/ Nova lorque, Routledge.

HERBERT-BOYD, Michelle (2007), Enriched by catastrophe: social work and social conflict after the Halifax explosion, Halifax, Fernwood Publising.

HEALY, Karen (2014), Social work theories in context, Londres, Palgrave McMillan.

HOFF, Marie e MCNUTT, John (Eds.) (1994), The global environmental crisis:Implications for social welfare and social work, Aldershot, Reino Unido, Ashgate.

JICKLING, Bob (1994), "Why I don“ t want my children to be educated for sustainable development: sustainable belief", Trumpeter, 11 (3), 2-8.

KEMP, Susan (2011), "Recentring environment in social work practice: necessity, opportunity, chalenge. British Journal of Social Work, 41 (6), 1198-1210.

KLEIN, Naomi (2007), The shock doctrine: the rise of disaster capitalism, Londres, Penguin.

KNIGHT, Louise (2010), Jane Addams: spirit in action, Nova lorque, W. W. Norton \& Company.

LAM, Lawrence (2007), "The association between climatic factors and childhood illnesses presented to hospital emergency among young children". International journal of environmental health research, 17, 1-8.

LEVINE, Daniel (1971), Jane Addams and the liberal tradition, Stevens Point: State Historical Society of Wisconsin.

MCKINNON, Jennifer e ALSTON, Margaret (eds.) (2016), Ecological Social work. Towards sustainability, Londres, Palgrave. 
MOLYNEUX, Rebecca (2010), "The practical realities of ecosocial work: review of the literature". Critical Social Work, 11 (2), 1-8.

MATTHIES, Aila-Leena, NÄRHI, Kati (Eds.) (2017), The Ecosocial Transition of Societies: The contribution of social work and social policy, London, Routledge.

MATTHIES, Aila-Leena, STAMM, Ingo, HIRVILAMMI, Tuuli, NÄRHI, Kati, (2019), "Ecosocial Innovations and Their Capacity to Integrate Ecological, Economic and Social Sustainability Transition", Sustainability, 11 (7), 2107. doi.org/10.3390/su11072107

NÄRHI, Kati (2004), The Ecological social approach in social work and the challenges to the expertise of Social work, Jyväskylä Studies in Education, Psychology and Social Research, 243, Jyväskylä, University of Jyväskylä.

NÄRHI, Kati e MATTHIES, Aila Leena Matthies (2016), “Conceptual and historical analysis of ecological social work" In Jennifer McKinnon e Margaret Alston (eds.), Ecological social work. Towards sustainability, (pp. 21-38), Londres, Palgrave.

NÄRHI, Kati e MATTHIES, Aila Leena (2001), "What is the Ecological (self) consciousness of Social Work? Perspectives on the relationship between social work and Ecology" In Aila-Leena Matthies, Katy Nárhi y Dave Ward ( eds.), Ecological social approach in social work (pp.16-53), Jyväskylä, Sophi.

NETTO, José Paulo (1992), Capitalismo monopolista e serviço social. São Paulo, Cortez Editora.

NORTON, Christine Lynn (2012), "Social Work and the environment: an ecosocial aproach", International Journal of Social Welfare, 21 (3), 299-308.

PAYNE, Malcon (1995), Teorías contemporáneas del trabajo social. Una introducción crítica, Barcelona, Ediciones Paidós.

PEETERS, Jef (2016), "Empowerment, resilience and social capital: building blocks for a sustainability transition", In Jennifer McKinnon e Margaret Alston (eds.), Ecological Social Work Towards sustainability, (pp. 197-217), Londres, Palgrave.

PEETERS, Jef (2012a), "The place of Social Work in susteinable development: towards ecosocial practice", International Journal of Social Welfare, 21, 287-298.

PEETERS, Jef (2012b), The place of Social Work in Susteinable development, Londres/Nueva York, Zed Books.

PINCUS, Allen e MINAHAN, Anne (1973), Social Work practice: Model and Method, Itasca, Peacock.

QUAGHEBEUR, Kerlijn, MASSCHELEIN, Jam. e GUYEN Hoai. (2004). Paradox of participation: givin or taking part? Journal of Community and Aplied Social Psychology, 14, 154-165.

RIBEIRO, Fernando Bessa (2017), Uma sociologia do desenvolvimento. V.N. Famalição: Edições Húmus.

RINKEL, Michaela e POWERS, Meredith (Eds.) (2019), "Social Work promoting community \& environmental sustainability: A workbook for global social workers and educators" Journal of Chemical Information and Modeling, 53, Rheinfelden, IFSW. doi.org/10.1017/CBO9781107415324.004

SCHMITZ, Cathryne, MATYÓK, Tom, JAMES, Channnelle e SLOAN, Lacey (2011), "The relationship between Social Work and environmental sustainability: implications for interdisciplinary practice", International Journal of Social welfare, 21, 278-286.

SILVA, Carlos e RIBEIRO, Fernando Bessa (2015), "Ciencias sociais, ética e bioetica: o caso do trabalho sexual", Revista Brasileira de Sociologia, 3 (5), 177-202. doi 10.20336/rbs.99.

SILVA, Maria das Graças (2010), Questão Ambiental e desenvolvimento sustentável: um desafio ético-político ao serviço social, São Paulo, Editora Cortez.

SILVA, Pedro, SACRAMENTO, Octavio, e MENDOÇA, Vera (2015), "Proximidade, reflexividade e crítica: O lugar da etnografia na intervenção social", Cuadernos de Trabajo Social, 28 (1), 27-37. doi. 10.5209/ rev_CUTS. 2015.v28.n1.46678.

SIPORIN, Max (1975), Introduction to Social work practice, New York, MacMillan.

SOUZA, Nalisa, SANTOS, Ana, SOUZA, Elaine e RAMOS, Jailson (2011) "Questao ambiental e política de meio ambiente: desafios ao Serviço social brasileiro" Revista de Políticas Públicas, v.15, 1, 121-129. 
WITHORN, Ann (1984), Serving the People: Social Services and Social Change. New York: Columbia University Press.

van WORMER, Katherine, Laura KAPLAN e Cindy JUBY (2012), Confronting oppression, restoring justice: From policy analysis to social action, Alexandria (VA): Council on Social Work Education. 